\title{
UN CASO DE QUERATITIS TRACOMATOSA (1)
}

\author{
Por los Dies. ALFredo DABANCENS L. y WALDO INOSTROZA C. \\ Hospital Manuel Arriarán. Policlinica de Lúrs y de Oftalmologia.
}

El tracoma es una de las infecciones a virus $^{1}$ que se conoce desde muy antiguo, porque ha azotado a la humanidad en todos los climas y en todas las edades de la vida, llegando, en un gran porcentaje de casos, a producir la ambliopía o la amaurosis.

Finalmente, en nuestros días su frecuencia se va haciendo cada vez menor en los grandes centros civilizados que han ido eliminando las condiciones más favorables para su propagación: la promiscuidad y la falta de higiene de las poblaciones. Esto equivale a decir que la profilaxis ${ }^{2}$ ha dado buenos resultados.

Además, el curso esencialmente crónico y rebelde al tratamiento, que era hasta hace poco una de las características de esta temible enfermedad ocular, ha experimentado un cambio notable con el uso đe los antibióticos, algunos de los cuales, como las sulfas ${ }^{3}$ y la penicilina ${ }^{4}$, ya han demostrado su manifiesta eficacia, pues logran detener y hasta curar la enfermedad cuando se administran oportunamente.

En el Hospital Arriarán recientemente hemos tenido ocasión de comprobar un caso de tracoma, circunstancia que por su rareza nos ha inducido a comunicar la observación.

\section{Observación.}

Er clia $B$ de mayo de I951 llegó a la Poltclinica de Lúes Ia niña Jesús R. B. (Observ. $N^{0}$ 51/86 351), de 13 an̆os de edad, quien ostensiblemente mostraba fotofobla $y$ epifora. en ambos ojos.

La traîa una bermana de 20 años, de quien obtuvimos una historia bastante incompleta y muy vaga, tanto que algunos datos los anotamos con interrogación, como por ejemplo, que la niña hublera andado a "los 7 años".

De todos mados, resaltaba de los antecedentes el hecho de que la niña sufría de los ojos desde hacia muchos años y que su enfermedad era atribuída por los familiares a que un dia se cayó dentro de una tina con hlpoclorito, donde lavaban ropas.

En nuestro interrogatcrio no encontramos antecedentes de lúes y tampoco el examen tísico reveló estigmas somáticos de lúes congénita. Nos llamó la atención el gran atraso pondoestatural de la niñá, quien a los 13 años 9 meses de edad sólo medía $123 \mathrm{~cm}$ y pesaba $\mathbf{2 4 1 / 2} \mathrm{kg}$.

El examen ocular mostraba ambos ojos con lnyección conjuntival difusa, infiltración corneal acentuada, con la consiguiente y ya señalada fotofobia y epífora. Había también discreta madarosis, pero lo más llamativo era la vascularización macroscópica de las corneas, en especial del ojo derecho.

Con la apreclación diagnóstica de querał1tis parenquimatosa, iniciamos los exámenes de rigor, citamos a la madre y mientras tanto envlamos a la niña al Serviclo de Ojos. El informe del oculista fué el siguiente:

"Ṕ́rpados congestionados en $O$. D. I. Fpi'fora y fotofobla discretos. Córneas con opacldades extensas vascularizadas".

"Al biomicroscopio se observan numerosas opacidades nodulares profundas y una gruesa red de vasos que en el $O$. D. compromete casi toda la córnea y en el $O$. I. particularmente la mitad superlor.

"No tiene aspecto de queratitls heredoIuética, iEscrofulasa?

"Tratamlento: Dlonina y atropina en gotas y pcrmada. - Dr. Inostroza".

Dos dias más tarde este informe se complementó con los siguientes exámenes:

(1) Presentación de la enferma a la Reunión clinica onf 7 de julio de 1951 . 
Reacción de Kahn: negativa en la niña $y$ en su hermana.

Reacclón de Mantoux al 1 x 1,000: negativa.

Sedimentacion: $20 \mathrm{~mm}$ en 1 hora.

Radioscapía de tórax: negativa.

Hemograma: nada de especial.

Como se ve, no habia base para confinmar la queratitis como luética, pero tampoco la habia para considerarla como escrofulosa.

Resolvimos ampltar la investigación, reactivando a la enferma y reiterando la citación de la madre que aun no venía.

La reactlvación se hizo con 3 inyecciones de Fenicilina $G$. procaína acuosa de $50,000 \mathrm{U}$ cada una, con 3 a 4 dias de intervalo y seguidas de un nuevo serocontrol al $10^{2}$ dia despues de la última inyección. El resultado fué completamente negativo y también negativo un segundo serocontrol en la hermana.

Teniamos entonces una queratitis crónica, a la cual no le podiamos poner apellido. Cotmo en la historia fíguraba el dato de que la lesión ocular aparecíó a raíz de caerse lá niña en una tina con hipoclorito, le preguntamos al oculista acaso podria aceptarse dicho agente químlco como causante de la enfermedad. Ia respuesta fué la siguiente:

"Estímo poco probable que las lesiones nodulares profundas de la cornea puedan tener origen en un agente quimico externo, el cual daría una lestón del epitelío corneal y en capa".

Repetido el Mantoux, esta vez al $1 \%$, volvió a resultar negativo.

En un tercer examen ocular la niña se dejó examinar en forma más detenida y entonces el oculista pudo llegar a la siguiente conclusión:

- Fay elementos para considerar esta queratitis de etiologia tracomatosa, pues hay pannus $y$ también hay cicatrices retráctiles en la confuntiva tarsal superior".

Tratamiento: Colirto de pentcilina de 10,000 $U \mathrm{X}$ cc cada hora y pomada sulfa-penicllina 4 veces al día.

La corroboractón dłagnóstica la obtuvimos a.lgunos días después cuanjo conseguimos hacer venir a la madre, quien nos dijo haber sufrido de tracoma ella y su hija mayor muchos años atrás.

Ademas, obtuvimos el dato de que nuestra enferma habiá sldo atendida antes en los Hospitales Roberto del Rî́o y Salvador.

Por intermedio de nuestra enfermera comprabamos que el 21 de junlo de 1942, o sea, hace 9 años, en el Elospital Roberto del Río se hlzo también el diagnóstico de tracoma en esta niñita. Desgraciadamente no hay datos sobre tratamlento efectuado, pero todo hace pensar que no se usaron anttblóticos, y por lo demás, la niña no volvló más a ese establecimlento, pues la abservación termina en esa misma fecha.

Nuestro co-relator, Dr. Inostroza, buscó los datos de esta chica en el Haspltal del Salvador. Allá tamblén figura el Ilagnjóstico de tracoma, pero con interrogactón. Como tratamiento se usó sulfato de cobre y nitrato de plata.

En una consulta muy pasterlor, más a menos en 1947, se le índícó collrio de penicilina, pero la enferma no volvió más.

La evolución en los 2 meses que lleva asistiendo a la Poljclínica de nuestro Hospital es favorable; durante los últimas 30 dias ha reclbido tratamiento antibiótico jocal con cojirlo de penteilina y pomada de sulfa-penicilina. Sus molestias princlpales; o sean, la totolobia y la epifora, han disminuido progreslvamente, hasta casi desaparecer. También se observa una menor congesttón de los párpados y no hay secreción conjuntlval, En cuanto a las corneas, naturalmente siguen infiltradas $y$ con su vascularización sin modificaclones apreciables, dada la cronicidad de 1a afecclón. En esta semana se ha iniciado tratamiento con penicilina lenta inyectable.

La serologia de la madre y del padre rueron totalmente negativas en nuestro servicio.

Creemos que este caso de queratitis tracomatosa nos ha proporcionado una buena oportunidad para apreciar cuán dificil es, en un primer momento, hacer el diagnóstico diferencial entre las queratitis parenquimatosa, la escrofulosis, la producida por cáusticos y la tracomatosa.

Tambièn pueden prestarse a confusión algunos casos de conjuntivitis primaveral y especialmente la conjuntivitis de Parinaud y la conjuntivitis folicular, afecciones que el especialista deberá descartar antes de asegurar la existencia de un tracoma.

\section{Resumen.}

Se presenta un caso de tracoma en una niñita de 13 años 9 meses de edad. La enfermedad había existido también en la madre y en una hermana mayor.

En la enfermita dominaba el cuadro un pannus bastante vascularizado y cicatrices en la conjuntiva tarsal superior de ambos ojos. 
La enfermedad tenía, por lo menos, 9 años de evolución.

El tratamiento con sulfa y penicilina local y con penicilina general acusa buenos resultados en un mes de observación.

\section{Summary.}

A case of Trachoma in a 13 year and 9 months old girl is described. Both her mother and an oider sister had the same disease. In the patient a rascularized pannus and scars in the superior tarsal conjunctivi of both eyes were the predominant symptoms. The disease had been present for 9 years. Local sulfanilamide and penicillin treatment and

intramuscular penicillin are producing good results after one month trial.

\section{Bibliografía.}

1.--British Journal of Ophthalmology. Vol. XiXIX, No 8, pág. 407. Agosto de 1945.

2.-ALGanaraz, R. - Manual Práctico de Oftalmologia. "비 Ateneo". Buenos Aires. 1948. Pág. 122.

3.- SIENA, JOSE A. - Arch. de Oftalmología de Buenos Aires. Vol. XVIII, $\mathbb{N}^{2} 12$, pág. 703. Diclembre de 1943.

4.-COSTI, C. y ALVAREZ M., T. - Arch. de la Sociedad oftalmológica Hispano-Americana. Vol. VI, págs. 649 y 650 . Jullo de 1943.

5.-ALGanaraz, R. - Manual Práctico de Oftalmología. "Fl Ateneo". Buenos Aires. 1948. Págs. 131, 132 y 133. 